\title{
Pesquisa de micro-organismos indicadores de qualidade higiênico-sanitária em sorvete expresso na Cidade de Mossoró, Rio Grande do Norte, Brasil
}

Research of microorganisms indicating hygienic-sanitary quality in express ice cream in the City of

Mossoró, Rio Grande do Norte, Brazil

Investigación de micro-organismos indicadores de calidad higiénico-sanitaria en helados soft en la

Ciudad de Mossoró, Rio Grande do Norte, Brasil

Recebido: 16/08/2021 | Revisado: 26/08/2021 | Aceito: 31/08/2021 | Publicado: 03/09/2021

Glauciana Priscilia da Silva ORCID: https://orcid.org/0000-0002-0253-3340 Universidade Federal Rural do Semi-Árido, Brasil

E-mail: priscilia_silva@hotmail.com

Renata Cristina Borges da Silva Macedo ORCID: https://orcid.org/0000-0003-4012-0659

Universidade Federal Rural do Semi-Árido, Brasil E-mail: renata.bsmacedo@gmail.com

Flávio Estefferson de Oliveira Santana ORCID: https://orcid.org/0000-0002-4675-2713 Universidade Federal Rural do Semi-Árido, Brasil E-mail: flavioestefferson@hotmail.com

Débora Midian Galdino Benevides ORCID: https://orcid.org/0000-0002-7804-2505 Universidade Federal Rural do Semi-Árido, Brasil E-mail: deboramidian15@gmail.com Bárbara Jéssica Pinto Costa

ORCID: https://orcid.org/0000-0002-8793-4142

Universidade Federal Rural do Semi-Árido, Brasil E-mail: barbarajessica3@hotmail.com

José Lucas Girão Rabelo

ORCID: https://orcid.org/0000-0002-0554-1637 Universidade Federal do Ceará, Brasil E-mail: joclucasrabelo@gmail.com Lidiane Pinto de Mendonça ORCID: https://orcid.org/0000-0001-5597-2446 Universidade Federal Rural do Semi-Árido, Brasil E-mail: lidiane.mendonca@outlook.com

Ana Carla Diógenes Suassuna Bezerra

ORCID: https://orcid.org/0000-0002-1039-5187

Universidade Federal Rural do Semi-Árido, Brasil E-mail: anacarla@ufersa.edu.br

Leônia Régia Costa da Silva

ORCID: https://orcid.org/0000-0001-8307-6948

Universidade Federal Rural do Semi-Árido, Brasil E-mail: leoniaregia@gmail.com

Alcinda Nathally Nogueira

ORCID: https://orcid.org/0000-0002-5380-7380

Universidade Federal Rural do Semi-Árido, Brasil

E-mail: nathally7@hotmail.com

Jeliel Fernandes Lemos

ORCID: https://orcid.org/0000-0003-3552-5926

Universidade Federal Rural do Semi-Árido, Brasil

E-mail: jeliellemos@hotmail.com

Karoline Mikaelle de Paiva Soares

ORCID: https://orcid.org/0000-0003-1578-3733

Universidade Federal Rural do Semi-Árido, Brasil E-mail: karolinesoares@ufersa.edu.br

\section{Resumo}

O sorvete é um alimento altamente consumido no Brasil e no mundo e que pode ser produzido à base de leite e ovos. Essas matérias-primas são bastante suscetíveis à degradação microbiana, podendo causar Doenças Transmitidas por 
Alimentos nos consumidores. Assim, o objetivo do presente trabalho foi avalizar a qualidade higiênico-sanitária de sorvete expresso na cidade de Mossoró, Rio Grande do Norte. Realizaram-se análises microbiológicas de coliformes totais e termotolerantes em dez amostras de sorvetes expressos. Todas as amostras foram positivas para a presença de coliformes totais. Das dez amostras estudadas, nove confirmaram a presença de coliformes termotolerantes quando incubadas em caldo Escherichia coli (EC). Aplicou-se o teste bioquímico do Citrato de Simmons dentre as amostras positivas para coliformes termotolerantes, sendo uma com resultado confirmativo. Assim, para que esse produto esteja apto à comercialização e ao consumo, faz-se necessária a participação dos órgãos competentes que atuam na fiscalização continuada de todo processo de produção do alimento, com o intuito de atender a legislação vigente e manter o controle de qualidade para o consumidor.

Palavras-chave: Doenças transmitidas por alimentos; Coliformes totais; Coliformes termotolerantes; Saúde pública.

\begin{abstract}
Ice cream is a highly consumed food in Brazil and worldwide and can be produced from milk and eggs. These raw materials are very susceptible to microbial degradation and can cause Foodborne Diseases in consumers. Thus, the objective of this work was to evaluate the hygienic-sanitary quality of ice cream express in the city of Mossoró, Rio Grande do Norte. Microbiological analyzes of total and thermotolerant coliforms were carried out in ten samples of ice cream express. All samples were positive for the presence of total coliforms. Of the ten samples studied, nine confirmed the presence of thermotolerant coliforms when incubated in Escherichia coli (EC) broth. Simmons' Citrati biochemical test was applied among the positive samples for thermotolerant coliforms, one with a confirmatory result. Thus, for this product to be suitable for commercialization and consumption, the participation of Organs competent bodies that work in the continuous inspection of the entire food production process is necessary, in order to comply with current legislation and maintain quality control for the consumer.
\end{abstract}

Keywords: Foodborne diseases; Total coliforms; Thermotolerant coliforms; Public health.

\title{
Resumen
}

El helado es un alimento altamente consumido en Brasil y en el mundo, que puede ser producido a base de leche y huevos. Estas materias primas son bastante susceptibles a degradación microbiana, pudiendo causar Enfermedades Transmitidas por Alimentos en los consumidores. Así, el objetivo del presente trabajo fue avalar la calidad higiénico sanitaria del helado soft en la ciudad de Mossoró, Rio Grande do Norte. Se realizaron análisis microbiológicos de coliformes totales y termotolerantes en diez muestras de helado soft. Todas las muestras fueron positivas para la presencia de coliformes totales. De las diez muestras estudiadas, nueve confirmaron la presencia de coliformes termotolerantes cuando fueron incubadas en caldo Escherichia coli (EC). Se aplicó el test bioquímico de Citrari de Simmons dentro de las muestras positivas para coliformes termotolerantes, siendo una con resultado confirmatorio. Así, para que ese producto sea apto para comercialización y consumo, es necesaria la participación de los organismos competentes que actúan en la fiscalización continua de todo proceso de producción de alimento, con la intención de atender la legislación vigente y mantener el control de la calidad para el consumidor.

Palabras clave: Enfermedades transmitidas por alimentos; Coliformes totales; Coliformes termotolerantes; Salud pública.

\section{Introdução}

Os produtos gelados comestíveis, como, por exemplo, o sorvete expresso ( soft ou italiano) é identificado como um sorvete de massa aerada ou cremosa onde toda consistência forma uma mistura homogênea através do processo de batimento, resfriamento e congelamento. Tal produto recebe essa classificação por intermédio do processo de fabricação e pela maneira como é apresentado (Soukoulis; Fisk; Bohn, 2014). Durante o processo de produção, transporte e armazenamento pode sofrer algum tipo de contaminação por patógenos, em virtude da sua composição, o que torna o alimento inadequado para o consumo desencadeando doenças em pessoas vulneráveis (Jadhav; Rault, 2014).

Durante a fabricação e ou no pós-processamento do sorvete, que é constituído por leites, derivados lácteos e outras matérias primas alimentares, podem ocorrer contaminação, principalmente porque muitos micro-organismos psicotróficos (que se desenvolvem e sobrevivem à baixas temperaturas) durante a etapa de produção e ou armazenamento (Silva; Vidal; Rossi Junior, 2016). Dependendo das condições ideais em que se encontra o sorvete, diferentes tipos de micro-organismos, incluindo os coliformes totais e termotolerantes, tem a capacidade de se proliferar, contaminando, assim, o alimento (Parussolo; 2014). Para manter a qualidade do produto final, a ANVISA, através da resolução RDC de $\mathrm{n}^{\circ} 12$ de 2 de janeiro de 2001 , estabelece 
os padrões microbiológicos nos produtos comestíveis gelados, listando limites para coliformes termotolerantes de 5,0 x10 NMP.g ${ }^{-1}$ (Brasil, 2001).

Os micro-organismos termotolerantes fermentam a lactose com produção de gás a $44,5^{\circ} \mathrm{C}$. Os coliformes pertencem à família Enterobacteriaceae, onde enquadram-se os gêneros Klebsiella e Enterobacter, que podem ser encontrados nos mais diversos ambientes, inclusive em solos e vegetais. já a Escherichia coli, que também são termotolerantes, apresenta como habitat primário o intestino humano e animal (Silva; Cavalli; Oliveira, 2006) de sangue quente que podem ocasionar doenças, além de promover intoxicações alimentares. A E. coli é uma bactéria gram-negativa que durante a lise da sua parede celular pode liberar complexos lipopolissacarídeos e endotoxinas, podendo causar diversos sintomas caso a bactéria entre na corrente sanguínea do indivíduo, como febre, diarreia, enjoo e vertigem (Hirsh; Zee, 2003).

Com a demanda do comércio em atender todo e qualquer público é preciso se atentar aos riscos relacionados ao consumo de alimentos. O controle de qualidade de alimentos começou a ser colocado em prática no século XIX, por meio das análises microbiológicas tradicionais, que se mantém presente até hoje, mesmo exigindo tempo e trabalho laboratorial excessivo (Senyk et al., 1987). Uma das maneiras de se conseguirem alimentos seguros é o investimento em técnicas de manipulação adequadas e no treinamento dos manipuladores. Esses esforços permitirão a prevenção de doenças veiculadas por alimentos (Levinger, 2005).

Segundo a Associação Brasileira das Indústrias e do Setor de Sorvetes - ABIS, as máquinas de processamento de sorvetes expressos, vêm trazendo uma nova alternativa de empreendimento para os brasileiros (ABIS, 2016). Esse tipo de sorvete muitas vezes é produzido sem nenhum controle de qualidade, principalmente, os obtidos de misturas artesanais. Intensificar na qualidade microbiológica é uma maneira de fornecer alimentos seguros, do ponto de vista higiênico-sanitário. Por esse motivo, o presente trabalho tem como objetivo quantificar coliformes em sorvetes expresso comercializado na cidade de Mossoró-RN, nos quais passaram por análise microbiológicas para identificar presença de patógenos no alimento.

\section{Metodologia}

\section{Amostras}

Dez amostras foram coletadas no centro da cidade de Mossoró-RN e escolhidas de modo aleatório em vendas de ambulantes que comercializam sorvete expresso. Os sabores selecionados foram: misto e creme com chocolate. Os sorvetes foram colocados em recipiente isotérmico, enumerados e cobertos com papel alumínio logo após a sua compra. Em seguida, foram levadas até o laboratório para serem analisados. Todos os materiais utilizados na coleta foram previamente sanitizados e esterilizados, a fim de evitar possíveis contaminações externas.

\section{Análises microbiológicas}

Foi realizada a técnica do Número Mais Provável (NMP), para a realização do estudo sobre a presença ou ausência de coliformes totais e tolerantes. Além disso, realizaram-se análises bioquímicas como prova definitiva da possível presença de enterobactérias, como meio de identificação (Silva et al., 2017).

\section{Técnica dos tubos múltiplos}

A técnica dos tubos múltiplos foi realizada com intuito de avaliar a presença de coliformes totais e coliformes termotolerantes. A investigação foi baseada através da Instrução Normativa nº 62, de 26 de agosto de 2003 (Brasil, 2003). As amostras foram preparadas de forma asséptica em fluxo laminar, onde pesaram-se as alíquotas de $25 \mathrm{~g}$ de cada sabor de sorvete para o preparo das diluições seriadas em $225 \mathrm{ml}$ de água peptonada previamente esterilizada. Foram utilizadas diluições decimais a partir da diluição $10^{-1}$ até a diluição $10^{-3}$, com três repetições cada. 
Utilizou-se o meio Caldo Lactosado Bile Verde Brilhante - CLBVB (Biobrás S. A.), em que os tubos foram incubados em banho-maria a $35^{\circ} \mathrm{C}$ por $24 \mathrm{e} 48 \mathrm{~h}$. As amostras que apresentaram confirmação positiva no crescimento de coliformes totais foram repicadas no meio $\mathrm{EC} \mathrm{a} 45^{\circ} \mathrm{C}$ em fluxo laminar e incubadas, novamente, em banho-maria por 24 a $48 \mathrm{~h}$. $\mathrm{O}$ resultado dessa técnica foi expresso em Número Mais Provável por grama de alimento (NMP/g).

Em seguida, foi utilizado o meio EMB para detectar a presença de Enterobacteriaceae, tendo como interesse a investigação de Escherichia coli. As amostras positivas, dos tubos contendo o meio EC, foram estriadas com auxílio da alça de platina nas placas de Petri com meio de cultura Citrato de Simmons e armazenadas em estufa bacteriológica por $24 \mathrm{~h}$ a $36^{\circ} \mathrm{C}$. Nesse caso, os corantes presentes no meio diferenciam a resposta de fermentação de sacarose e ou lactose por microorganismo. Os coliformes resultam em colônias de cor pretas-azuladas; já as Escherichia coli, verde metalizado, devido a rápida fermentação da lactose.

\section{Prova bioquímica}

\section{Teste do Citrato}

As amostras positivas no meio EMB, ou seja, aquelas que apresentaram colônia de coloração verde brilhante, seguiram para avaliação através de teste de citrato para a realização de teste bioquímico (Siqueira, 1995), onde foi feito o estriamento no tubo de ensaio contendo citrato de Simmons. Em seguida, foi levado à estufa por 24h. Cada amostra positiva foi estriada e inoculada em tubos contendo ágar citrato de Simmons, podendo supor que os resultados positivos apresentavam alterações da coloração verde para a azul.

Nesse estudo, ocorre uma alteração de pH azul de bromotimol que passa de neutro (verde) para alcalino (azul) com o crescimento microbiano, presumindo-se possivelmente a presença de enterobactérias, representadas principalmente pela espécie Escherichia coli.

\section{Resultados e Discussão}

De acordo com a Tabela 1, as amostras que tiveram resultado positivo igual ou superior a 1100 NMP são consideradas insatisfatória pela legislação (Brasil, 2001). Segundo Cunha, Magalhães e Bonnas (2012) essa alta contagem de coliformes pode indicar uma má higienização, desde o processo de produção pelos manipuladores como também pelos próprios consumidores, ou seja, a contaminação pode ter sido originada da matéria-prima, da inadequação da limpeza ou sanitização do local onde o alimento é produzido ou pela contaminação pós-processamento, fazendo com que se torne inviável ao consumo direto.

Tabela 1. Resultado dos testes de coliformes totais e termotolerantes nas amostras de sorvete expresso.

\begin{tabular}{ccc}
\hline Amostras & $\begin{array}{c}\text { Coliformes totais } \\
(\text { NMP*/g) }\end{array}$ & Coliformes termotolerantes (NMP/g) \\
\hline 1 & $>1100$ & $>1100$ \\
2 & $>1100$ & 36 \\
3 & $>1100$ & $>1100$ \\
4 & $>1100$ & $>1100$ \\
5 & $<3,0$ & $<3,0$ \\
6 & $>1100$ & 36 \\
7 & $>1100$ & 11 \\
8 & $>1100$ & 43 \\
9 & $>1100$ & 93 \\
10 & $>1100$ & $>1100$ \\
\hline
\end{tabular}


*NMP: Número Mais Provável. Fonte: Autores.

Na técnica dos tubos de Número Mais Provável, do total de sorvetes expressos analisados, nove amostras tiveram resultados positivos para coliformes totais, sendo confirmadas pela presença de formação de gás nos tubos de Durham (Figura $1)$.

Figura 1. Formação de gás no interior do tubo de Durham.

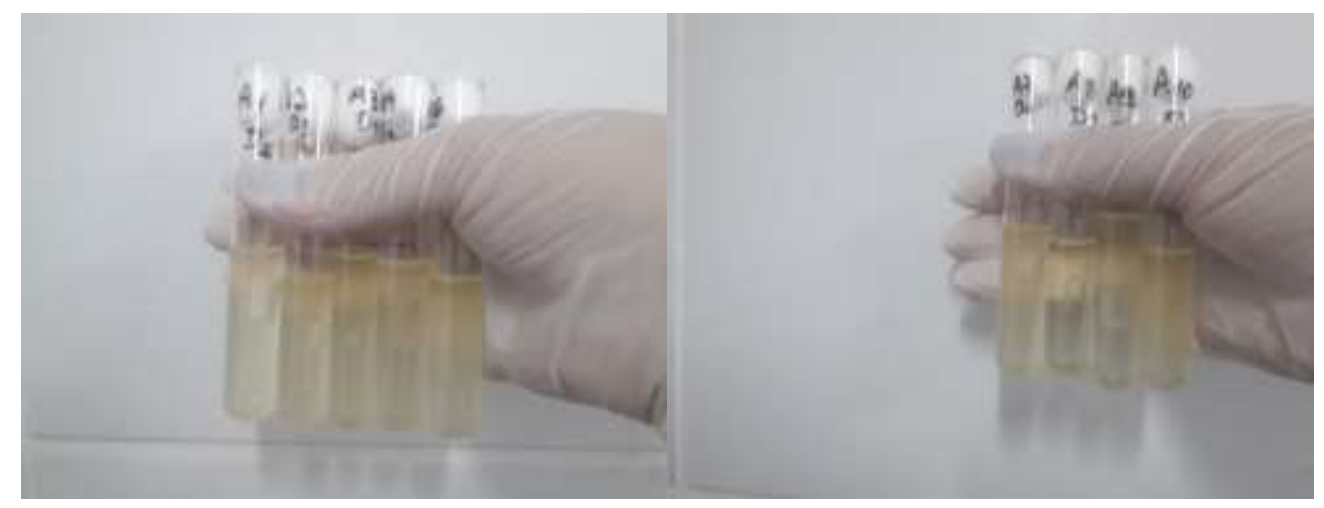

Fonte: Autores (2021).

Resultado semelhante foi apresentado por Souza et al. (2015) onde foram analisadas cinco amostras de cinco estabelecimentos por duplicata, sendo que em seu estudo constataram que mais de $70 \%$ das amostras apresentaram resultado positivo de coliformes totais e $50 \%$ das mesmas estavam acima dos valores estabelecidos pela legislação em relação aos coliformes termotolerantes, apresentando assim, condições insatisfatórias para o consumo.

Dias et al. (2006) ao analisar a qualidade microbiológica de 30 amostras de sorvete tipo italiano, constaram que quatro (13\%) das amostras apresentaram níveis inferiores à 5,0 x10 NMP.g ${ }^{-1}$, concluindo que as amostras se encontravam em condições satisfatórias. Esse resultado diverge com os encontrados no presente estudo. Porém, acaba sendo semelhante com resultados achados de Galdioli, Bagatin e Valoto (2017), que também gerou resultado satisfatório ao analisar cinco amostras de sorvetes expressos, comercializado em Campo Mourão-PR. Apesar de todas as amostras conterem coliformes totais, nenhuma delas foi detectada a presença de coliformes termotolerantes. Duas dessas amostras eram de escala industrial; as outras, quiosque e barracas. Entretanto, as coletas dos estabelecimentos de pequeno porte tiveram resultado melhor quando comparado com as empresas de grande porte.

A contagem de E. coli é utilizada como o principal indicador de contaminação fecal. De todas as amostras avaliadas, a Amostra 2, do presente estudo, foi positiva para E. coli quando semeadas em placas EMB, e confirmada pelo teste bioquímico do citrato, como apresentado na Figura 2. 
Figura 2. Avaliação bioquímica através do teste do citrato de Simmons para confirmação da possível presença de Escherichia coli.

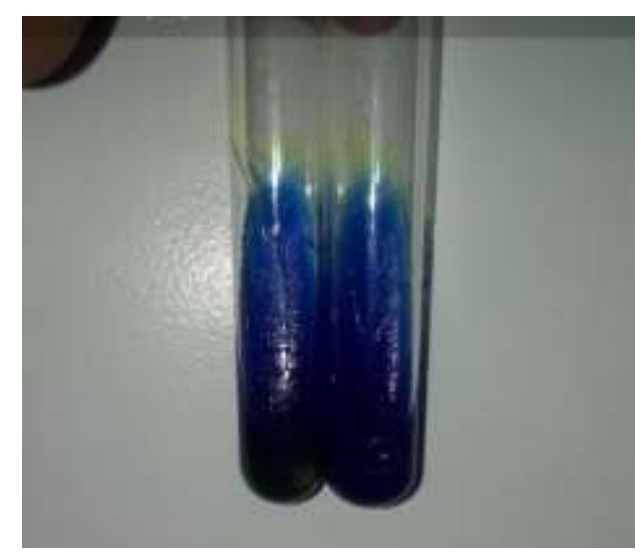

Fonte: Autores (2021).

Alguns microrganismos utilizam o citrato como fonte de carbono na ausência de glicose ou lactose. O meio ágar de Simmons contém o citrato como fonte de carbono, onde é degradado pela enzima citrase produzindo óxido oxalacético e acetato. Esse teste é realizado em tubos de rampa devido a presença de oxigênio ser indispensável. Após o micro-organismo utilizar o citrato e oxidar o mesmo, ocorre a liberação de $\mathrm{CO}_{2}$. Nessa reação ocorre a mudança do pH tornando o meio alcalino, ocorre uma combinação entre o $\mathrm{CO}_{2}$ que foi liberado e água formando o carbonato de sódio, a presença deste último faz aumenta o pH do meio reacional detectado através da mudança de coloração verde para azul forte (Silva et al., 2017).

Ainda considerando o estudo de Souza et al. (2015), todas as amostras analisadas tiveram resultados positivos para Escherichia coli. Provavelmente, o material fecal esteve em algum momento em contato com o alimento durante processamento de produção, por falta de higiene dos manipuladores e, principalmente, pela má higienização dos objetos durante a comercialização (Alves e Ueno, 2010; Paula et al., 2014). Damer et al. (2015) analisaram 21 amostras de sorvete, sendo sete sorvetes do tipo italiano, sete sorvetes de massa artesanal e sete sorvetes de massa industrializada. A E. coli foi encontrada em 42,8\% em sorvete de massa artesanal e 14,3\% em sorvetes industrializados; nos sorvetes do tipo italiano não houve confirmação de E. coli. Os sorvetes de massa artesanal apresentaram um resultado bastante considerado em relação a presença da E. coli. É importante salientar que algumas linhagens de E. coli causam enfermidades gastrointestinais com elevada gravidade (JAY,2005).

\section{Conclusão}

De modo geral, foi detectada nas amostras de sorvete expresso a presença de coliformes totais e termotolerantes. É fundamental que as máquinas de armazenamento e produção do alimento sejam higienizadas da maneira apropriada para não favorecer a proliferação de micro-organismos causadores de doenças. Com isso, deve existir práticas sanitárias não apenas no processo de pasteurização e congelamento como, também, no pós-processamento, no intuito de promover a não contaminação e crescimento de micro-organismos indesejáveis.

\section{Referências}

Alves, M. G., \& Ueno, M. (2010). Restaurantes self-service: segurança e qualidade sanitária dos alimentos servidos. Rev. Nutr., 23 (4), 573-580.

ABIS- Associação Brasileira das Indústrias e do Setor de Sorvetes (2016). Estatística da produção e consumo de sorvetes no Brasil. http://www.abis.com.br/estatistica_producaoeconsumodesorvetesnobrasil.html.

Brasil (2001). Regulamento Técnico sobre padrões microbiológicos para alimentos. Diário oficial da República Federativa do Brasil. 
Research, Society and Development, v. 10, n. 11, e345101119478, 2021

(CC BY 4.0) | ISSN 2525-3409 | DOI: http://dx.doi.org/10.33448/rsd-v10i11.19478

Brasil (2003). Metodos Analísticos Oficiais para Analises Microbiológicas para Controle de Produtos de Origem Animal e Água. Diário oficial da República Federativa do Brasil.

Cunha, F. M. F., Magalhães, M. B. H., \& Bonnas, D. S (2012). Desafios da gestão da segurança dos alimentos em unidades de alimentação e nutrição no Brasil: uma revisão. Context da Aliment - Rev. Comport. Cult e Soc., 1 (2), 414.

Damer, J. R. S., Garcia, V., Gusmão, A. A. \& Moresco, T. R. (2015). Qualidade higiênico-sanitária de sorvetes tipo italiano e de massa (artesanal e industrializado) comercializados na região noroeste do Rio Grande do Sul, Brasil. Demetra: Food, nutrition e health, 10 (4), 821-834.

Dias, F. G. B., Pereira, M. J. G., Ferreira, D. C., Araujo, L. O., \& Queiroz, E. A. T. (2006). Condições higiênico-sanitárias e pesquisa de listeria monocytogenes em sorvetes do tipo italiano comercializados na cidade de Fortaleza. XXV Congresso Brasileiro de ciência e tecnologia de alimento.

Galdioli, K. U., Bagatin, M. C., \& Valoto, A. L. O. (2017). Determinação de Coliformes em Sorvetes Expressos Comercializados em Campo Mourão-PR. Revista Iniciare, 2 (1), 2-9.

Hirsh, D. C., e Zee, Y. C. (2003). Microbiologia veterinária. Guanabara Koogan.

Jadhav, A. S., \& Raut, P. D. (2014). Evaluation of microbiological quality of ice creams marketed in Kolhapur city, Maharashtra, India. International Journal of Current Microbiology and Applied Sciences, 3 (9), 78-84.

Jay, J. M. (2005). Microbiologia de alimentos. Artmed.

Levinger, B. (2005). School feeding, school reform, and food security: connecting the dots. Food Nutrition Bulletin, 26, 170-178.

Parussolo, G., et al. (2014). Avaliação microbiológica de sorvetes comercializados no município de Frederico Westphalen. Blucher Food Science Proceedings, $1(1), 1-2$.

Paula, C. M. D., Casarin, L. S., \& Tondo, E. C. (2014). Escherichia coli O157:H7- patógeno alimentar emergente. Vigilância Sanitária em Debate, 2 (4), 23 33.

Senyk, G. F., Kozlowski, S. M., Noar, P. S., Shipe, W. F, \& Bandler, D. K. (1987). Comparison of dry culture medium and conventional plating techniques for enumeration of bacteria in pasteurized fluid milk. Journal of Dairy Science, 70, 1152-1158.

Silva, H I., Vidal, A. M. C., \& Rossi Junior, O. D. (2016). Análises de coliformes totais e termotolerantes em produtos derivados lácteos e sorvetes. Revista de Ciência e Tecnologia, 8, 1-5.

Silva, M. P., Cavalli, D. R., \& Oliveira, T. C. R. M. (2006). Avaliação do padrão coliformes a $45^{\circ} \mathrm{C}$ e comparação da eficiência das técnicas dos tubos múltiplos e PetrifilmTM EC na detecção de coliformes totais e Escherichia coli em alimentos. Ciência e Tecnologia de Alimentos, 26 (2), 352-359.

Silva, N., Junqueira, V. C. A., Silveira, N. L. A., Taniwaki, M. H., Gomes, R. A. R., \& Okazi, M. M. (2017). Manual de métodos de análise microbiológica de alimentos e água. Bluncher.

Siqueira, R. S. (1995). Manual de microbiologia de alimentos. Embrapa.

Soukoulis, C., Fisk, I. D., \& Bohn, T. (2014). Ice cream as a vehicle for incorporating health-promoting ingredients: conceptualization and overview of quality and storage stability. Food Science and Food Safety, 13, 627-655.

Souza, J. M., Brito, E. C. G., Santos, E. C. G., \& Silva, G. A. S. (2015). Análise microbiológica dos sorvetes self-service sabor chocolate da cidade de SinopMT. Demetra: Alimentação, nutrição e saúde, 10 (4), 857-866. 